\section{Case Reports in Dermatology}

\title{
Treatment of Multiple Actinic Keratosis and Field of Cancerization with Topical Piroxicam $0.8 \%$ and Sunscreen $50+$ in Organ Transplant Recipients: A Series of 10 Cases
}

\author{
Virginia Garofalo ${ }^{a} \quad$ Alessandra Ventura ${ }^{a} \quad$ Sara Mazzillia ${ }^{a}$ Laura Diluvio ${ }^{a}$ \\ Luca Bianchi $^{a} \quad$ Luca Toti $^{c}$ Giuseppe Tisone ${ }^{c}$ Massimo Milani ${ }^{b}$ \\ Elena Campione ${ }^{a}$ \\ ${ }^{a}$ Department of Systems Medicine, Division of Dermatology, University of Rome \\ Tor Vergata, Rome, Italy; ${ }^{b}$ Medical Department, Difa Cooper, IFC Group, Caronno \\ Pertusella, Italy; ${ }^{C}$ Department of Experimental Medicine and Surgery, University of Rome \\ Tor Vergata, Rome, Italy
}

\section{Keywords}

Organ transplant recipients · Actinic keratosis · Piroxicam · Sunscreens

\begin{abstract}
Organ transplant recipient (OTR) subjects are at high risk of skin cancer such as squamous cell carcinoma and basal cell carcinoma. Actinic keratosis (AK) is considered the precursor of these non-melanoma skin cancers. Sun protection is mandatory in subjects with AK and this preventive strategy is very important in OTR. Treatment of the field of cancerization is also crucial to reduce the risk of recurrence of skin lesions in AK and non-melanoma skin cancer patients. Activation of cyclooxygenase 1 and 2 enzymes plays an important role in the pathogenesis of skin cancers. Topical application of cyclooxygenase inhibitors such as diclofenac and, more recently, piroxicam has shown to reduce AK lesions in immunocompetent subjects. A medical device containing piroxicam and SPF 50+ sunscreen filters $(P+S S)$ has been demonstrated to be effective in reducing AK lesions and improving the field of cancerization. We report the effect of $\mathrm{P}+\mathrm{SS}$, applied for 16 weeks, in a case series of 10 OTR subjects with
\end{abstract}


multiple AK lesions. $\mathrm{P}+\mathrm{SS}$ treatment was associated with a relevant $\mathrm{AK}$ lesion reduction (>75\%) in 7 patients (with a complete clearance in 3 subjects) with an improvement in the field of cancerization. This medical device could be considered a promising long-term curative and preventive treatment in OTR patients at high risk of non-melanoma skin cancers.

(C) 2017 The Author(s)

Published by S. Karger AG, Basel

\section{Introduction}

Organ transplant recipients (OTR) have an increased risk for developing skin cancer, and non-melanoma skin cancers (NMSCs) represent a significant cause of morbidity and mortality in this clinical setting [1]. Actinic keratosis (AK) is considered the precursor lesion of NMSC [2]. In subjects with immune depression, the relative risk of squamous cell carcinoma (SCC) and AKs is substantially higher compared with immunocompetent patients [3]. In OTR subjects, SCC, the most aggressive form of NMSC, is 5 times more frequent than basal cell carcinoma (BCC) and this ratio differs from the general population where BCC is more common than SCC [1]. AK and SCC in OTR subjects commonly involve UV-light-exposed areas [4]. The management of NMSCs in OTRs presents a variety of clinical challenges for physicians [5]. All patients should receive extensive education on UV avoidance and sun protection [6]. The carcinogen-preventive approach is mandatory in areas of field of cancerization and is recommended to reduce morbidity and mortality associated with the progression from AKs to invasive SCC in OTRs [7]. Cyclooxygenase (COX) 1 and 2 enzyme upregulation is involved in the pathogenetic process of AKs and NMSCs [8]. Piroxicam is a non-steroidal anti-inflammatory drug (NSAID) characterized by a non-selective COX-1 and COX -2 inhibition activity [9]. We investigated the effects of a medical device in topical formulation containing piroxicam $0.8 \%$ and sunscreen $(\mathrm{SPF} 50+)(\mathrm{P}+\mathrm{SS})$ on the clearance rates of multiple AKs and field of cancerization in OTR subjects.

\section{Subjects}

We report a 10-case series of OTR patients, 8 men and 2 women, mean age $67 \pm 6$ years (6 with liver transplantations and 4 with kidney organ transplantations), with histories of extensive AKs. On average, the OT procedure was performed $10 \pm 6$ years before (range 221 years). The main immunosuppressive treatments were tacrolimus in 8 patients and everolimus in 2 subjects. Four subjects were also treated with mycophenolic acid. All these patients were treated with a cream formulation of P+SS, twice daily for 16 weeks. We evaluated, as primary objective, the evolution of AK lesion number, evaluated by clinical mapping of visible lesions, and, as secondary endpoint, the evolution of the Actinic Keratosis Erythema Scale Atrophy (AKESA) score [10] assessing erythema, scale, and atrophy of a target AK lesion. The AKESA score is based on the assessment of the clinical presence of erythema, scale, and atrophy on a target AK lesion. A numeric value from 0 to 3 was attributed to each AK clinical feature (baseline maximum AKESA score: 9) up to complete remission (disappearance of all features in the target lesion, AKESA endpoint score: 0). We also assessed the percentage of treated AKs with complete $(100 \%)$ or partial $(\geq 75 \%)$ clearance and evaluated skin tolerability with this medical device. Finally, we also evaluated at baseline and after 16 weeks the following dermoscopic features of the target lesion: erythematous pseudonetwork (strawberry pattern) on the facial lesions, erythematous background on the other 
sites, whitish-yellowish surface scales, and atrophic hypopigmented areas, according to Zalaudek et al. [11].

\section{Results}

At baseline, the total lesion count was 51 (44 lesions Grade 1-2 and 7 lesions Grade 3) with an average lesion number of 5.1 per patient. Adherence to treatment was evaluated by counting the empty tubes returned at each visit. Three out of 10 patients showed complete clinical clearance after 16 weeks of treatment with P+SS. Four additional patients showed a marked ( $\geq 75 \%$ lesion count reduction) improvement in their overall AK lesion count in the treatment area. A relevant improvement was also observed under dermoscopic observation of the target lesions (Fig. 1). Two patients showed a 30\% lesion count reduction in the treated area. The overall AK lesion count decreased from 51 at baseline to 13 at the end of treatment, representing a 75\% reduction in lesion count. Grade 1 and 2 lesions respond better than Grade 3 type lesions. In these lesions, the AKESA score was also markedly reduced after treatment: the total AKESA score was 81 and $23(-72 \%)$ before and after P+SS, respectively. A clinical improvement of field cancerization in 1 subject is shown in Figure 2. Adverse events were limited to mild local irritation. No systemic side effects were reported. The good local tolerability was in line with clinical data published [26, 27].

\section{Discussion}

Immunosuppressive treatment in OTR is mandatory to maintain an adequate graft function [12]. However, immunosuppression carries an increased risk for the development of cancers, especially epithelial skin cancer [13]. Skin cancers are a major part of OT-related morbidity and mortality [14]. In OTR subjects, BCC and SCC account for more than $90 \%$ of skin cancer manifestations [15]. We reported here the efficacy of a medical device containing $\mathrm{P}+\mathrm{SS}$ in a case series of 10 OTRs. Piroxicam is an enolic benzothiazine and a member of the oxicam series, structurally different from diclofenac [16]. In contrast with diclofenac, piroxicam is characterized by a potent COX-1 inhibitory action [17]. The agent suppresses the synthesis of pro-inflammatory enzymes such as prostaglandins (mainly PgE) and tromboxanes [18]. Piroxicam inhibits polyamine production by blocking ornithine decarboxylase induction [19]; these pathways are involved in skin carcinogenesis [20]. In contrast to diclofenac, piroxicam is also able to induce apoptosis and suppress metalloproteinase 2 and 9 activities $[21,22]$, the most prominent proteinase family associated with tumorigenesis [23]. Recently, a medical device containing P+SS has been evaluated in AK subjects. Prospective clinical trials have shown that sun filters in AK subjects prevent the appearance of new AK lesions [24], therefore combining a cyclooxygenase inhibitor and sunscreen filters in a single product could have a strong rationale. In the trials evaluating the efficacy of diclofenac in AK, subjects were advised to concomitantly also use sunscreens and to avoid excessive exposure to the sun [25]. This two-component medical device could therefore have the advantage of improving subject adherence to the therapy. The clinical efficacy of P+SS in the treatment of AK was evaluated in two controlled multicenter trials $[26,27]$ involving a total of 108 subjects. The treatment of $\mathrm{P}+\mathrm{SS}$ in this clinical setting induced a reduction in AK lesions of more than 55\%. This medical device was also very effective in an immune-depressed subject with a history of Kaposi sarcoma and multiple AK lesions unresponsive to previous ablative 
treatments [28]. Piroxicam, in contrast with diclofenac, expresses antioxidant [29] and antiviral [30] actions. The latter could be of relevant interest because infection of human papillomaviruses is associated with an increased risk of NMSC [31]. In renal transplant subjects, Berkhout et al. [32] showed that human papillomavirus tends to persist in premalignant skin lesions. However, the anti-viral action of piroxicam from a clinical point of view should at the moment be considered speculative regarding this clinical setting.

\section{Conclusions}

The use of piroxicam and sunscreen in OTRs is safe due to the lack of local and systemic immunogenic effect, which is not recommended in this class of patients. Moreover, the usefulness of this new formulation combining the anticancer effect of piroxicam with the chemopreventive action of sunscreens could be considered a new long-term therapeutic strategy, which is mandatory in these OTRs. Prospective studies are needed to investigate the efficacy and safety of this therapy in greater numbers of these patients.

\section{Statement of Ethics}

The authors have no ethical conflicts to declare.

\section{Disclosure Statement}

M.M. is an employee of Difa Cooper Spa.

\section{References}

1 Euvrard S, Kanitakis J, Claudy A: Skin cancers after organ transplantation. N Engl J Med 2003;348:16811691.

2 Sober AJ, Burstein JM: Precursors to skin cancer. Cancer 1995;75:645-650.

-3 Ulrich C, Kanitakis J, Stockfleth E, Euvrard S: Skin cancer in organ transplant recipients - where do we stand today? Am J Transplant 2008;8:2192-2198.

4 Stockfleth E, Ulrich C, Meyer T, Christophers E: Epithelial malignancies in organ transplant patients: clinical presentation and new methods of treatment; in Cancers of the Skin. Berlin/Heidelberg, Springer, 2002, pp 251-258.

5 Martinez JC, Otley CC, Stasko T, Euvrard S, Brown C, Schanbacher CF, Weaver AL: Defining the clinical course of metastatic skin cancer in organ transplant recipients: a multicenter collaborative study. Arch Dermatol 2003;139:301-306.

-6 Naylor MF, Boyd A, Smith DW, Cameron GS, Hubbard D, Neldner KH: High sun protection factor sunscreens in the suppression of actinic neoplasia. Arch Dermatol 1995;131:170-175.

-7 Vatve M, Ortonne JP, Birch-Machin MA, Gupta G: Management of field change in actinic keratosis. Br J Dermato 2007;157:21-24.

8 Buckman SY, Gresham A, Hale P, Hruza G, Anast J, Masferrer J, Pentland AP: COX-2 expression is induced by UVB exposure in human skin: implications for the development of skin cancer. Carcinogenesis 1998;19:723-729.

-9 Blanco F, Guitian R, Moreno J, De Toro FJ, Galdo F: Effect of antiinflammatory drugs on COX-1 and COX-2 activity in human articular chondrocytes. J Rheumatol 1999;26:1366-1373.

10 Campione E, Paternò EJ, Candi E, Falconi M, Costanza G, Diluvio L, Terrinoni A, Bianchi L, Orlandi A: The relevance of piroxicam for the prevention and treatment of nonmelanoma skin cancer and its precursors. Drug Des Devel Ther 2015;9:5843. 
11 Zalaudek I, Giacomei J, Argenziano G, et al: Dermoscopy of facial nonpigmented actinic keratosis. Br J Dermatol 2006;155:951-956.

12 Pascual M, Theruvath T, Kawai T, Tolkoff-Rubin N, Cosimi AB: Strategies to improve long-term outcomes after renal transplantation. N Engl J Med 2002;346:580-590.

13 Gutierrez-Dalmau A, Campistol JM: Immunosuppressive therapy and malignancy in organ transplant recipients. Drugs 2007;67:1167-1198.

14 Lindelöf B, Sigurgeirsson B, Gäbel H, Stern RS: Incidence of skin cancer in 5,356 patients following organ transplantation. Br J Dermatol 2000;143:513-519.

-15 Berg D, Otley CC: Skin cancer in organ transplant recipients: epidemiology, pathogenesis, and management. J Am Acad Dermatol 2002;47:1-20. Brogden RN, Heel RC, Speight TM, Avery GS: Piroxicam. Drugs 1984;28:292-323.

Hawkey CJ: COX-1 and COX-2 inhibitors. Best Pract Res Clin Gastroenterol 2001;15:801-820.

Gordon D, Lewis GP: Effects of piroxicam on mononuclear cells. Inflammation 1984;8:S87-S102.

Reddy BS, Nayini J, Tokumo K, et al: Chemoprevention of colon carcinogenesis by concurrent administration of piroxicam, a nonsteroidal antiinflammatory drug with d, l- $\alpha$-difluoromethylornithine, an ornithine decarboxylase inhibitor, in diet. Cancer Res 1990;50:2562-2568.

20 Pairet M, Engelhardt G: Differential inhibition of COX-1 and COX-2 in vitro and pharmacological profile in vivo of NSAIDs; in Improved Non-Steroid Anti-Inflammatory Drugs: COX-2 Enzyme Inhibitors. The Netherlands, Springer, 1996, pp 103-119.

21 Mirshafiey A, Vaezzadeh F, Khorramizadeh MR, Saadat F: Effect of piroxicam on matrix metalloproteinase 2 and apoptosis. Int J Tissue React 2004;26:1-7.

22 Mazumder MK, Bhattacharya P, Borah A: Inhibition of matrix metalloproteinase- 2 and 9 by Piroxicam confer neuroprotection in cerebral ischemia: an in silico evaluation of the hypothesis. Med Hypotheses 2014;83:697-701.

23 Schmalfeldt B, Prechtel D, Härting K, et al: Increased expression of matrix metalloproteinases (MMP)-2, MMP-9, and the urokinase-type plasminogen activator is associated with progression from benign to advanced ovarian cancer. Clin Cancer Res 2001;7:2396-2404.

-24 Thompson SC, Jolley D, Marks R: Reduction of solar keratoses by regular sunscreen use. N Engl J Med 1993;329:1147-1151.

25 Nelson C, Rigel D, Smith S, et al: Phase IV, open-label assessment of the treatment of actinic keratosis with 3.0\% diclofenac sodium topical gel (Solaraze). J Drugs Dermatol 2003;3:401-407.

-26 Babino G, Diluvio L, Bianchi L, Orlandi A, Di Prete M, Chimenti S, Milani M, Campione E: Long-term use of a new topical formulation containing piroxicam $0.8 \%$ and sunscreen: efficacy and tolerability on actinic keratosis. A proof of concept study. Curr Med Res Opin 2016;32:1345-1349.

27 Puviani M, Galloni C, Marchetti S, Sergio Pavone P, Lovati S, Pistone G, Caputo V, Tilotta G, Scarcella G, Campione E, Diluvio L: Efficacy of a film-forming medical device containing sunscreen (50+) and piroxicam $0.8 \%$ in actinic keratosis and field cancerization: a multicenter, assessor-blinded, 3 month trial. Curr Med Res Opin 2017;19:1-5.

28 Scotti E, Deledda S, Milani M: Efficacy of a film-forming medical device containing piroxicam and sun filters in the treatment of multiple actinic keratosis lesions in a subject with a history of kaposi sarcoma. Case Rep Dermatol 2016;8:254-261.

-29 Bartosiewicz G, Mezes M, Nemet J: Changes in lipid, peroxide, and anti-oxidant blood levels during piroxicam (Hotemin) treatment. Ther Hung 1992;41:67-71.

-30 Guilford JM, Pezzuto JM: Natural products as inhibitors of carcinogenesis. Expert Opin Investig Drugs 2008;17:1341-1352.

-31 Bavinck JN, Neale RE, Abeni D, Euvrard S, Green AC, Harwood CA, de Koning MN, Naldi L, Nindl I, Pawlita M, Pfister H: Multicenter study of the association between betapapillomavirus infection and cutaneous squamous cell carcinoma. Cancer Res 2010;70:9777-9786.

32 Berkhout RJ, Bavinck JN, ter Schegget J: Persistence of human papillomavirus DNA in benign and (pre) malignant skin lesions from renal transplant recipients. J Clin Microbiol 2000;38:2087-2096. 


\section{Case Reports in Dermatology}
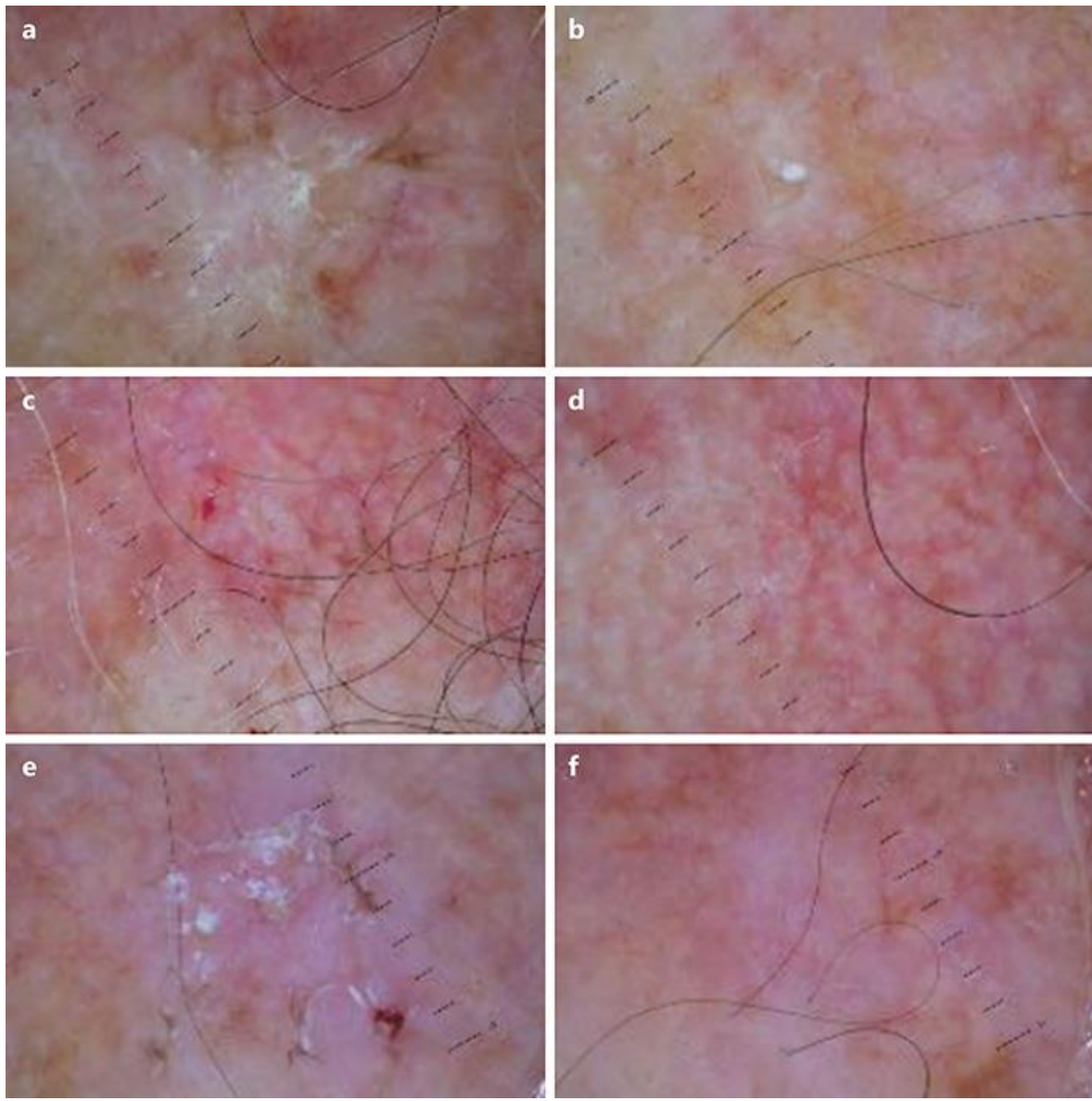

Fig. 1. Dermoscopy features of the target lesion. a, c, e Baseline. b, d, f After 16 weeks.
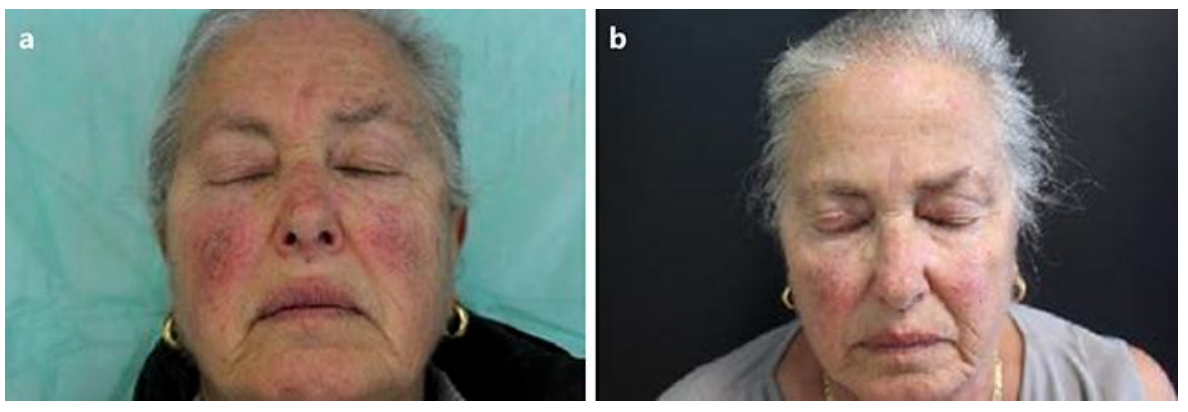

Fig. 2. Clinical field cancerization evolution. a Baseline condition. b After 16 weeks. 